\title{
A Study on the Subjectivity on Organ Donation of Nursing Students
}

\author{
Sunyoung Jang \\ Dept. of Nursing, Hanseo University, 46 Hanseol Ro, Haemi-myun, Seosan-si, \\ Chungcheongnam-do, 369-709, Korea \\ sjang@hanseo.ac.kr
}

\begin{abstract}
The objectives of this study are to understand the subjectivity of organ donation perceived by nursing students, to describe the characteristics of each type, and also to understand the categorization of organ donation by applying the Q-methodology. Total of 20 students of nursing department in A college were asked to classify total of 46 sentences of statement about organ donation. The collected data was analyzed by using the QUANL PC Program. In the results of this study, the nursing students' perception of organ donation was divided into two factors. The types of subjectivity on organ donation included the 'type of seeking for the vitalization measures for organ donation' and the 'type of considering the characteristics of organ donors'. This study provided the basic data for understanding and educating the perception of organ donation of clinical nurses.
\end{abstract}

Keywords: Organ donation, Nursing student, Subjectivity, Q-Methodology, Nurse

\section{Introduction}

\subsection{Necessity of study}

Owing to the development of new diagnoses and treatments with the advancement of modern medical science, many diseases that used to be regarded as impossible to be treated in the past are cured now [1], and especially, the organ donation that has started being developed since the 1950s, is established as a treatment for patients with end-stage organ failure in the advanced countries, and it is also recognized as a treatment that could increase the quality of life [2]. To solve the shortage of organ donation, the foreign countries are developing and effectively operating diverse organ donation vitalization programs such as the latent brain dead report system, aggressive organ procurement program, support for family, and active national promotion. It is reported that the number of brain death organ donation is gradually increasing through these programs [3]. As it is important to put efforts for understanding the latent brain death early and recommending the organ donation to be led to the actual donation, the medical personnel involved in treatment by directly contacting the brain-dead patients plays a very important role [3][4].

As the core manpower that occupies the biggest part in the healthcare medical site, and also has the most contact with subjects, the nurses should provide the high-quality and safe nursing to the subjects within the limited time in the rapidly-changing healthcare medical environment [5]. For the successful achievement of many organ donations and transplants, the

Article history:

Received (February 24, 2020), Review Result (March 28, 2020), Accepted (May 6, 2020) 
nurses' roles in charge of providing the information about transplant, direct nursing, education, counseling, and support to donors, recipients, and their families, intervening and adjusting the overall procedures, and performing researches related to transplant are very important [6]. The subjectivity of perception when dealing with subjects in the nursing site has great effects on their nursing. Thus, it is important to understand the perception of nurses and pre-service nurses.

There are not many researches on organ donation targeting the nursing students. And as a methodology that could understand the characteristics of each type in accordance with the subjectivity structure of human, originated from the doers' perspective instead of the researcher's assumption [7], the Q-methodology is a proper research method for verifying the types of nursing students' perception of organ donation by considering the subjectivity of the subjects as the nursing students' perception of organ donation is their subjective and unique experience.

Thus, this study aims to provide the basic data necessary for developing the differentiated educational programs in accordance with the characteristics of each type of organ donation targeting the pre-service nurses before going out to the nursing site where the organ donation is successfully performed, by understanding the subjectivity structure of organ donation in the perspective of nursing students.

\subsection{Purpose of study}

The objectives of this study are to provide the data to nursing students who start the organ donation by examining the types of subjective perception and the characteristics of the types of organ donation targeting the nursing students by applying the Q-methodology, and also to provide the basic data for suggesting the strategies when educating the nursing students who just start the organ donation. The concrete objectives of this study are as follows.

1) The nursing students' subjective perception of organ donation is classified.

2) The characteristics of each type of nursing students' perception of organ donation are analyzed and described.

\section{Method of study}

\subsection{Design of study}

To achieve the objectives of this study, after considering the literature, media data, and preceding researches on organ donation, this study finds the subjectivity viewing the types of subjective perception on organ donation targeting the nursing students who have experienced organ donation.

\section{2. $Q$ population and $Q$ sample selection}

In order to extract the effects of organ donation and comprehensive statements focusing on the current nursing students, the Q-population was drawn through the consideration of domestic \& foreign relevant literature, open-ended questionnaire, and individual in-depth interview. Through this process, on top of drawing a total of three areas and about 200 Qpopulations, this study drew about 100 Q-populations by integrating the collected literature through the consideration of domestic \& foreign literature. Going through the procedure of reviewing and modifying the extracted Q-populations, finally, total of 46 samples with high discrimination were selected. 


\subsection{Design of study}

As qualitative research emphasizing the individuals' inertia focusing on differences in the semanticity or importance within individuals instead of differences between individuals, the Q-methodology is based on the small sample doctrine [8]. According to this doctrine, when the p-sample gets larger, many people are concentrated in a single factor, so that the characteristics are not clearly revealed. As the p-sample, this study selected total of 20 nursing students who voluntarily agreed to participate in this study after fully explaining the objectives of this study to them.

\subsection{Classification and data analysis method}

In the Q-classification process, the research subjects who have been selected as p-sample, make the voluntary definition of organ donation of each individual by classifying the statements of Q-sample in the forced normal distribution method [9]. The data was collected from 26 nursing students of OO college by using the Q-card. It took mostly 30-45 minutes for each research subject to complete the Q-classification. In the distribution of Q-sample, the research subjects classified the statements selected as Q-sample into strong affirmation and too strong denial depending on the importance based on their own opinions. The statement (Q1) about organ donation was classified in the 12-point scale. After that, further interview with the subjects was performed in relation to the statements classified into the two extremes. For the Q-factor analysis, the Principle Component Factor Analysis(varimax) was used. The classification of types was selected by considering the results of variously inputting the number of factors on the basis of Eigen value as 1.0 or up, and total explanatory variate. For the collected data, the transformed score given as much as 1-12points was changed into score focusing on the forcedly distributed card on the Q-sample distribution table. By coding the given transformed score in the order of Q-sample number, it was processed through the principal factor analysis by the QUANL PC Program. The data analysis was processed by using the QUANL pc program [10].

\subsection{Ethical considerations for the subject}

Before starting this research, the subjects were asked for their voluntary consent, and then explained that they could stop anytime during the research. To guarantee the rights, privacy, and confidentiality of personal information of the subjects, all the data collected through this study was processed, encoded, and Q-sorted as uninscribed in the whole process of data analysis for the confidentiality.

\section{Result of study}

\subsection{Structure of Q-Type}

In the results of conducting the Q-factor analysis on the nursing students' subjectivity on organ donation by using the QUANL pc program, there were two types.

\subsection{Type specific characteristics in smartphone addiction}

Type of Seeking for the Vitalization Measures for Organ Donation: The subjects belonging to the type 1 were total of 11 people. The statements in which the subjects of type 1 showed the strong affirmation included 'The most important thing for organ donation is self- 
determination. $(\mathrm{Z}=1.86)$ ', 'In case when having an experience of receiving an explanation of organ donation from medical personnel, the probability of organ donation increases. $(\mathrm{Z}=1.68)$ ', and 'I hope to receive the education of organ donation. $(\mathrm{Z}=1.49)$ ' [Table 1]. In the type 1, the subject with the highest factor weight was No.15(1.2077), and the statements agreed the most were No. 36 and No. 18. In the characteristics of the type 1, they thought that the sharing of experience or preliminary education of organ donation would have positive effects on the organ donation. They thought that it would be necessary to secure organs for transplant through various methods for vitalizing the organ donation in accordance with the increase of organ transplant, and the promotion of organ donation would be important for this. They said that the public service advertisement or the improvement of people's perception could increase the organ donation, and the permission of brain-death donation would bring a new life to many people. However, they did not aim to encourage the organ donation to their own families. Thus, the type 1 was named the 'type of seeking for the vitalization measures for organ donation'.

Type of Pessimism: The subjects belonging to the type 2 were total of nine people. The statements in which the subjects of the type 2 showed the strong affirmation included 'The organ donation by brain death is high. $(Z=1.97)$ ', 'The organ donation is avoided because of Confucian thoughts of Korea. $(Z=1.57)$ ', and 'In case of the married, the probability of organ donation is high. $(Z=1.53)^{\prime}$ [Table 1]. In the type 2, the subject with the highest factor weight was No. 6 (1.6383), and the statements agreed the most were No. 4 and No. 7. In the characteristics of the type 2, they thought of the vitalization measures for organ donation considering the characteristics of organ donors. They thought that the probability of organ donation would be high in case of brain-dead patients. They also judged that there would be more organ donation in case when married or having children. They thought that the surgery would be avoided due to the influence of Confucianism in Korea. They thought that the people with religion would show the high tendency of organ donation based on their dedicated belief. Even though they thought that the organ donation could be institutionally encouraged by public service advertisement, they did not aim to recommend the organ donation to their own families as there would be a lot of other medical treatments. Thus, the type 2 that was still showing this perception, was named the 'type of considering the characteristics of organ donors'.

Table 1. Representative items of organ donation and $\mathrm{Z}$-score $(\mathrm{N}=20)$

\begin{tabular}{|c|c|c|c|c|}
\hline Factor & No & Description & Mean (SD) & Z-score \\
\hline \multirow{4}{*}{$\begin{array}{c}\text { Factor } 1 \\
(\mathrm{~N}=11)\end{array}$} & 36 & $\begin{array}{c}\text { The most important thing for organ donation is self- } \\
\text { determination. }\end{array}$ & $10.09(2.256)$ & 1.86 \\
\cline { 2 - 5 } & 19 & $\begin{array}{c}\text { In case when having an experience of receiving an } \\
\text { explanation of organ donation from medical } \\
\text { personnel, the probability of organ donation } \\
\text { increases. }\end{array}$ & $7.82(1.940)$ & 1.68 \\
\cline { 2 - 6 } & 34 & $\begin{array}{c}\text { I like to provide the information about organ } \\
\text { donation to my family. }\end{array}$ & $6.64(2.111)$ & -2.41 \\
\cline { 2 - 6 } & 35 & $\begin{array}{c}\text { I hope that the government provides the cost for } \\
\text { organ donation. }\end{array}$ & $4.73(1.794)$ & -1.90 \\
\cline { 2 - 6 } & 27 & $\begin{array}{c}\text { In case when having an occupation, the probability } \\
\text { of organ donation increases. }\end{array}$ & $3.17(1.722)$ & -1.71 \\
\hline Factor 2 & 4 & The organ donation by brain death is high. & $6.67(2.828)$ & 1.97 \\
\hline
\end{tabular}




\begin{tabular}{|c|c|c|c|c|}
\hline (N=9) & 7 & $\begin{array}{c}\text { The organ donation is avoided because of } \\
\text { Confucian thoughts of Korea. }\end{array}$ & $4.56(1.590)$ & 1.57 \\
\cline { 2 - 5 } & 13 & $\begin{array}{c}\text { In case of the married, the probability of organ } \\
\text { donation is high. }\end{array}$ & $5.00(2.449)$ & 1.53 \\
\hline 34 & $\begin{array}{c}\text { I like to provide the information about organ } \\
\text { donation to my family. }\end{array}$ & $5.33(2.291)$ & -2.19 \\
\hline 23 & $\begin{array}{c}\text { The organ donation is the best method to save } \\
\text { dying patients. }\end{array}$ & $6.56(3.206)$ & -1.51 \\
\hline & 45 & $\begin{array}{c}\text { It would be great if the adolescents are also } \\
\text { empowered for organ donation. }\end{array}$ & $7.11(1.900)$ & -1.46 \\
\hline
\end{tabular}

\section{Discussion}

In the results of this study, the types of subjectivity on organ donation perceived by nursing students were divided into the 'type of seeking for the vitalization measures for organ donation' and the 'type of considering the characteristics of organ donors'. And this study aims to discuss the characteristics of each type.

The type 1 shown in this study was the "type of seeking for the vitalization measures for organ donation'. They think that organ donation should be increased as the organ transplant is increasing. Thus, they are preferentially considering the methods to solve the shortage of organs. Also, they think that each individual has the autonomy of body selection, and selfdetermination is the most important than other surrounding influences. They thought that the vitalization of organ donation through education or public service advertisement could be supported at the national level, and also judged that the number of domestic organ donors would increase in case when there is institutional support.

The type 2 was the 'type of considering the characteristics of organ donors'. They think that the tendency of organ donors should be considered as the organ donation is necessary for organ transplant. They thought that the organ transplant could be vitalized if a proper policy would be established by setting up strategies based on the analysis of the tendency of organ donors. The active concentration would be needed in the level of institution or government.

This study explored the nursing students' subjective perception of organ donation, and then divided and analyzed it into two types. In the results of this study, most of the nursing students thought that the organ transplant would be continuously developing in the future as one of the last treatments of incurable diseases in the aging society. Thus, as a method of supporting insufficient organs, currently, the organ transplant was mentioned as the most suitable method. To encourage the organ transplant, on top of the support in the level of government or institution, the supports like education for changes in individuals' perception would be needed as well.

In the characteristics of each type, there were the 'type of seeking for the vitalization measures for organ donation' mentioning the necessity to establish the institutional support or measures for vitalizing the organ donation, and the 'type of considering the characteristics of organ donors' mentioning the necessity to support suitably after understanding the characteristics of organ donors. This study on the subjectivity could be used as the basic data of organ donation support programs that grab attention recently. Moreover, it could be used as the basic data for the development of differentiated educational programs by suggesting the subjective structure of perception of organ donation and the characteristics of each type targeting the nursing students as preservice medical personnel.

However, this study targeted only a college, and could not select the research subjects by considering the factors having effects on the perception of organ donation, so that it would be 
limited to generalize the results of this study. Thus, it would be needed to additionally verify the types by composing the Q-sample equipped with various backgrounds through further researches.

\section{Conclusion}

In order to establish the basic data necessary for seeking the vitalization measures for organ donation based on the subjective data analyzed by exploring the nursing students' subjective perception of organ donation, this study applied the Q-methodology. In the results of this study, the types of organ donation perceived by nursing students included the 'type of seeking for the vitalization measures for organ donation' and the 'type of considering the characteristics of organ donors'.

This study provided the basic data necessary for introducing or applying policies for vitalizing the organ donation support programs in the future by classifying the nursing students' subjectivity on organ donation. Based on the results of this study analyzing the types of nursing students' perception of organ donation and also verifying the characteristics of each type, the educational programs could be developed by considering the characteristics of each type. This study also suggests additional research on the analysis of types by selecting samples considering various factors, and also qualitative research for verifying various factors having effects on the nursing of the subjects of organ donation.

\section{References}

[1] M. H. Sung, E. Y. Son, and S. E. Lee, "A study on knowledge and attitude of Nurses regarding brain death organ donation," Journal of Korean Clinical Nursing Research, vol.12, no.1, pp.125-135, (2006)

[2] H. S. Ha, J. S. Jeong, Y. R. Chae, J. J. Hong, I. O. Kim, M. S. Yi, D. B. Moon, and S. G. Lee, "Psychosocial adjustment of the organ transplantation recipients in Korea," J Korean Soc Trans., vol.21, no.1, pp.269-281, (2007)

[3] J. Lee and S. Kim, "The knowledge and attitude of medical students towards the organ donation," J. of Korean Society for Transplantation, vol.22, no.2, pp.120-129, (2008)

[4] W. Lee, J. Kwak, and O. Moon, "A study on the analysis of relative factors of intensive care unit nurses' attitude in brain death organ donation," J. of Korean Society for Transplantation, vol.15, no.2, pp.217-224, (2001)

[5] C. S. Wong and K. S. Law, "The effects of leader and follow emotional intelligence on performance and attitude: An exploratory study," The Leadership Quarterly, vol.13, no.3, pp.243-274, (2002) DOI: 10.4324/9781315250601-10

[6] S. J. Byun, H. K. Kim, A. R. Kim, H. S. Ha, and K. O. Joen, "Task analysis of Korean transplantation nurse practitioner," J Korean Acad Nurs., vol.33, no.2, pp.179-188, (2003) DOI: 10.4040/jkan.2003.33.2.179

[7] W. Stephenson, "Q-methodology, interbehavioral psychology and quantum theory," Psychol Record, vol.32, pp.235-248, (1982)

[8] S. M. Whang, S. W. You, J. Y. Kim, and R. G. Kim, "Consumer types and cultural consumption characteristics of Korean society: Who Spends for What Reasons?" Journal of Human Subjectivity, vol.13, pp.25-39, (2006)

[9] S. Jang, "The subjectivity for open adoption of nursing students," International Journal of Advanced Nursing Education and Research, vol.3no.1, pp.59-64, (2018) DOI: 10.21742/ijaner.2018.3.1.10

[10] M. Wang, S Kim, and S Jang, "Study of subjectivity on death in Korean elderly," International Journal of Elderly Welfare Promotion and Management, vol.2, no.2, pp.37-42 (2018) DOI: 10.21742/ijewpm.2018.2.2.07 